Article

\title{
Saying It Like It Is? Power, Participation and Research Involving Young People
}

\author{
Emma Davidson \\ Centre for Research on Families and Relationships, University of Edinburgh, EH8 9LN, Edinburgh, UK; \\ E-Mail: e.c.davidson@ed.ac.uk
}

Submitted: 31 March 2017 | Accepted: 27 July 2017 | Published: 26 September 2017

\begin{abstract}
Developments in the conceptualisation of childhood have prompted a fundamental shift in young people's position within social research. Central to this has been the growing recognition of children's agency within the landscapes of power between child participants and adult researchers. Participatory research has rooted itself in this paradigm, gaining status from its principles of social inclusion and reciprocity. While participatory research has benefitted from a growing theoretical analysis, insight can be deepened from reflexive accounts critiquing participation 'in the field'. This article presents one such account, using the example of an ethnographic study with young people living in a 'disadvantaged' housing estate in the UK. It describes how efforts to 'enable' young people's participation were simultaneously embraced, contested, subverted and refused. These, often playful, responses offered rich insight into how the young participants viewed themselves, their neighbourhood, and 'outsiders' efforts to give them voice. The article concludes by emphasising the importance of conceptualising participation not simply as a set of methods, but as a philosophical commitment which embraces honesty, inclusivity and, importantly, the humour that can come from this approach to research.
\end{abstract}

\section{Keywords}

children's rights; power; participation; resistance; UK; voice; young people

\section{Issue}

This article is part of the issue "Promoting Children's Participation in Research, Policy and Practice", edited by Jo Aldridge (Loughborough University, UK).

(C) 2017 by the author; licensee Cogitatio (Lisbon, Portugal). This article is licensed under a Creative Commons Attribution 4.0 International License (CC BY).

\section{Introduction}

The conceptualisation of children as active in the construction of their own social worlds has gained recognition since the 1990s. Oft-cited alongside the 'new social studies of childhood' (James, Jenks, \& Prout, 1998; Mayall, 2000) this perspective critiques Piagetian understandings of children as 'human becomings' who lack the competencies of adults. Instead, it addresses children as 'human beings' who, in the here and now, are in possession of opinions, views and perspectives which deserve to be taken seriously (Qvortrup, 2009; Uprichard, 2008). This swell of interest in the 'new studies of childhood' is often made with reference to the Convention on the Rights of the Child (CRC), adopted in November 1989 (Cashmore, 2002; Grover, 2004; Lundy, 2007; Matthews, Limb, \& Taylor, 1999; Shier, 2001; Sinclair, 2004). The CRC, and Arti- cle 12 in particular, has not only made children's participation in decisions affecting their own lives a fundamental right, but systematically links these rights to social inclusion, agency and empowerment (Freeman, Nairn, \& Sligo, 2003).

This paradigmatic shift has, in the succeeding years, become a "powerful and pervasive mantra" (James, 2007 , p. 261), not least within academic social research traditions of the Minority World. Researchers within childhood and youth studies have increasingly turned to epistemological approaches which recognise children and young people as producers of knowledge about their own lives, and which redress perceived power differentials between child participants and adult researchers (Percy-Smith \& Thomas, 2010; Tisdall, 2015; Tisdall, Gadda, \& Butler, 2014). Participatory research, and its fundamental connection to solidarity with oppressed and 
disempowered people (see Maguire, 2008, for discussion of participation from a feminist perspective), has rooted itself in this paradigm by offering the methodological foundations upon which children and young people's 'voices' can be heard (Grover, 2004; Hill, 2006).

A growing body of literature has engaged critically with the discourse and practices of children and young people's participation (Gallagher, 2008; Skelton, 2007; Tisdall, 2008; Tisdall \& Punch, 2012) and the notion that participatory methods can 'give' them voice (James, 2007; Komulainen, 2007; Soto, Swadener, Kincheloe, \& Jipson, 2005). These debates have centred around the normative presumption that participation is inherently 'good' or 'valued' (Nelson \& Wright, 1995; Skelton, 2007; Tisdall, 2008), with some going so far as to suggest participatory research is a "cliché" (Cornwall \& Jewkes, 1995, p. 1668). Central to this critique is not only a challenge to the dichotomous theorisation of power upon which participatory research is often based but also a belief that power, and its effects, can be reduced or minimised.

The aim of this article is to provide a critical and reflective account of participation 'in the field'. It does this by exploring the landscapes of power operating within an ethnographic study involving young people growing up in a Scottish housing estate, named here as 'Robbiestoun' (both this, and participants' names used in this article, are pseudonyms). In this respect, it follows Gallagher (2008) and Alanen (2014), who suggest that theoretical insights can be deepened by examining research practices claiming to be participatory. The study in question combined participant observation with a toolkit of participatory methods. Used both in a youth work and community setting, the approaches were designed to allow a wide range of young people to reflect and express their views and experiences of antisocial behaviour. Efforts at enabling young people's participation were simultaneously embraced, resisted, subverted and refused. The article focuses on the more challenging aspects of participation which often find themselves written out of accounts of participation, or sanitised for academic publication. These, often playful and humorous, responses did not, the article concludes, represent non-participation. Rather, they illuminate the ways in which research practices can allow for deeper insight into how young people view themselves, their social worlds, and 'outsiders' efforts to 'give' them voice.

\section{Participation, Voice and Power}

There is no firm definition of participatory research: it spans a continuum of different types of projects, and can be undertaken in many different ways. Where it is frequently discussed is with reference to the degree of engagement participants have "within and beyond" the research encounter (Pain \& Francis, 2003, p. 46). Participation can thus refer to process (sharing or taking part in an activity), or an outcome (specifically taking part in decision making). Such engagement has, in turn, become aligned to the methods and approaches employed, with creative, practical or 'task based' activities being associated with sharing ownership and the co-production of knowledge with participants (Askins \& Pain, 2011; Christensen \& James, 2008; Kellett, 2010; Pain, 2004). Morrow and Richards (1996, p. 98) suggest that using methods which are "non-invasive, non-confrontational and participatory, and which encourage children to interpret their own data" is one step towards addressing the disparities in power between adults and children.

Others have pointed to child-centred research methodologies as a means of making children and young people's right to be heard and have their views taken into account central to the research process (Aldridge, 2012; Barker \& Weller, 2003; Coad, 2007; Van Blerk \& Kesby, 2009). This is often expressed in terms of 'giving' children and young people a 'voice', with voice being an ethical and moral requirement. The "more authentic" the voice, the more the balance of power shifts away from adult researchers (Wyness, 2013, pp. 341-342). Visual and non-verbal methods make an important challenge to 'voice' based forms of participation which have dominated children's participation, partly as a consequence of the CRC (Horgan, Forde, Martin, \& Parkes, 2017, p. 278). This is particularly important in relation to research with individuals and groups who do not have the necessary cognitive or verbal skills or confidence to take part in conventional qualitative methods. However, these benefits are not unique to child participants, and their value can stretch across generations and contexts (see for example Aldridge, 2016; Cameron et al., 2013; Wickenden \& Kembhavi-Tam, 2014).

While evidence has demonstrated the value in these methods, there is a paradoxical situation whereby participatory methods simultaneously promote the competence of the child, yet call for creative research methods. This not only intimates that 'conventional' research is inadequate for reconfiguring adult-child power relations, but that children and young people require 'special' methods. If, like Punch (2002) and Thomson (2007), children and young people are considered competent social actors, it follows that researchers should not necessarily require 'child-friendly' data collection methods. This position takes us beyond the binary categories of the adult and child which, for Ryan (2008), is equally problematic, since it renders many of the conceptual tools for understanding children and young people's lives unworkable.

For Thomson (2007) the issue with 'child friendly' approaches is not the methods in themselves. Rather the concern is in the way such approaches prioritise childadult categorisations, while simultaneously neglecting how age intersections with generation, and other identities, such as class, gender or race. Horgan (2017) similarly critiques the tendency within children's rights discourses to conceptualise children as independent right holders removed from their social, economic and cultural context. In broad response to these concerns, theorisations of childhood and youth have begun to emphasise the dy- 
namic and relational aspects of children's lives (Hanson, 2016; Tisdall \& Punch, 2012). This viewpoint recognises that individuals, regardless of age or generation, live interdependently (see Wyness, 2013; also, Horgan, 2017). The value of this analysis is that it does not discount the existence of child-adult power relationships, nor the possible vulnerabilities of children and young people, but places them within the context of generational practices, negotiated interdependencies and wider societal structures (Plows, 2012).

The rhetoric of the authentic 'voice' of the child, and its association to participatory research, has also been debated. James (2007) has argued that such efforts risk simplifying and reducing the complexity of children as social actors. Looking globally, Tisdall and Punch (2012) have raised concerns that notions of agency and rights are Minority World conceptualisations, and therefore privilege certain types of 'voices'. Komulainen (2007) is equally critical of the notion of 'giving' children a voice, emphasising instead voice as a social process, with not only the involvement of a speaker and a listener, but ambiguity in interpretation. Spyrou (2011) states that in order for childhood research to deal with the problem of representation, we must first reflect on the social processes through which 'children's voices' are produced. While not dismissing the concept of voice, he concludes by stating that "reflective researchers need to move beyond claims of authenticity and account for the complexity behind children's voices by exploring their messy, multi-layered and non-normative character" (Spyrou, 2011, p. 151).

The notion of 'voice' is intimately connected to power, and the desire to use methods which challenge the disempowered social position of children. It is also-like power-messy, complex and multi-layered. Gallacher and Gallagher (2008) argue that participatory approaches often describe power as a "commodity" possessed by the adult researcher and denied to young participants. While such principles are congruent with a prochild stance (Roberts, 2000), this model sees power as dichotomous both in the researcher-researched relationship and wider society. Gallagher (2008, p. 403) proposes an alternate view of power:

It may therefore be unhelpful to imagine children's participation as a process by which adults, who 'have' power, empower children by 'giving' them some of this power. It might be more interesting to look at precisely how power is exercised, through a whole range of different techniques, in the interactions between the individuals involved.

While not underestimating adult power in research settings, this analysis highlights the value of adopting a more dynamic and relational understanding of power and voice, and how they intersect with method. Holland, Renold, Ross and Hillman (2010, p. 363), for example, found that power dynamics amongst young people affected the 'par- ticipatory' agenda, with stronger voices drowning out quieter members. Likewise, Gallagher's (2008, p. 3) own classroom research suggests that dichotomous conceptualisations of power fail to acknowledge the ways in which young people may "redirect, contest or refuse participatory techniques". He concluded that participants' attempts to subvert or resist his presence were expressions of these power dynamics. Hill (2012) faced similar challenges, with young people using strategies of resistance, such as physical absence, to disengage with the research. Plows (2012), meanwhile, has discussed the ways in which expressions of agency by young people which challenge professional values can be interpreted as 'problem' or 'difficult' behaviour. Here, an ideological position is associated to agency, whereby the participating child or young person is learning to be a good citizen when they do the 'right' thing (Hanson, 2016). This position can potentially neglect ambiguous forms of agency which, as researchers may be professionally challenging, but offer insight into the social networks and social conditions which shape children and young people's lives.

Before moving onto the empirical example, it is concluded that there is nothing inherently empowering or child-centred about participatory methods (Gallacher \& Gallagher, 2008), nor can a particular method make claims to being 'more' authentic or 'more' participatory. Rather, the capacity of an approach to be participatory depends on the nature of the social relations between those involved, the ways in which methods are practiced, and the extent to which individual capacity and social conditions are observed and accounted for. As Guariento (2010, p. 95) suggests:

Researchers need to recognise the imperfections of a relationship that is necessarily unequal, rather than trusting specific techniques to solve these contradictions through their inherent power. Participatory techniques may help children's voices to come through more powerfully by leaving more space for individual styles of interaction and by opening more channels for expression; they cannot be relied on, however, to act as a tool-kit to redress a power imbalance.

The distinctiveness of participatory research should thus lie in its philosophical concern with mutuality, equality and empowerment, with methods being selected not for their creativity, but as most appropriate for democratising processes of knowledge production.

\section{Study Background: Saying It Like It Is}

The research which this article draws upon was a yearlong participatory ethnography based in Robbiestoun (a pseudonym), a predominantly social housing estate on the outskirts of a Scottish city. Robbiestoun spans three distinct housing estates which historically have suffered from poor housing conditions, poverty and unemployment. Despite being the focus of a long term programme 
of demolition and new build, the area continues to suffer from a range of problems associated with 'disadvantaged' localities, including above average crime rates, rising unemployment and poor levels of educational attainment. Using a local youth club as the research base, it explored how young people growing up in a 'disadvantaged ${ }^{1}$ place defined and understood antisocial behaviour. The overall aim was to capture how such definitions are constructed and, in particular, the ways in which 'the antisocial' can impact on young people's spatial and social relationships.

The study was situated in a body of literature which suggests that UK antisocial behaviour policy is a means of regulating conduct (Flint \& Nixon, 2006) and casts a moralising spotlight on young people and those living in social housing estates (Squires, 2008). The aim was to select an area of study which was typical of public imaginings of the social housing estate, as a 'problem' place, with 'problem' people (see Damer, 1989). As part of a pilot study, several youth clubs were visited, and initial interviews were conducted with youth workers. These focused on perceptions and experiences of youth antisocial behaviour; responses by the police and antisocial behaviour professionals; and the extent and nature of youth services. Notably Robbiestoun was the only pilot area where young people were invited to lead this first discussion, a factor which influenced its selection as the research site. Punitive responses to youthrelated antisocial behaviour and heavy surveillance of public spaces, youth workers informed me, was a key concern amongst the young people they worked with. The young people present suggested that antisocial behaviour policies were an expression of wider societal attitudes to youth, felt unfairly targeted by police, and expressed concern over initiatives designed to prevent them socialising in groups. As Abs commented, "It just shows you how young people are seen...classed as rats, like vermin" (Abs, 17). Youth workers concurred, arguing that the rhetoric around antisocial behaviour had enabled a wholesale change in the way young people are 'placed' in society: "[antisocial behaviour] has created something...perhaps potential hate for authority later in life. It has affected [young people's] experience of being young" (Tom, Youth Worker).

The pilot study revealed that antisocial behaviour was an expressed issue for a number of young people, and local youth services. Robbiestoun Youth Centre was willing to give permission to use the youth club as a base for the study, and more importantly, initial discussions with some young people living locally were positive. The pilot was formative in the study design, which came to prioritise concern for the disempowered social position of young people, and the relative absence of mechanisms for voicing these issues to those in authority. The aim was to shift away from research as a site where participant's views are 'collected' or 'given', towards it being viewed as a social, relational and interactive process (Harden, Scott, Backett-Milburn, \& Jackson, 2000, para. 5.3).

\section{A Toolkit Approach to Participation}

To do this, a toolkit approach was used, which combined participant observation and qualitative interviews, with a range of well documented 'creative' methods (discussed below). The crucial element of the toolkit was that methods were employed non-hierarchically, with no single approach being judged as offering a more authentic form of participation. Rather, multiple methods were used to engage with a wide range of young people and their diverse experiences, in a way that was sensitive to their assets and personal preferences. This, simultaneously, avoided the tyranny of method, whereby methods assumed as more participatory drive out other possibilities (Cooke \& Kothari, 2008, pp. 8-9).

The research commenced with weekly participant observation at two sessions at the Robbiestoun Youth Centre: an employability project for 16-25 year olds and an after-school session for young people aged 12-15. Since the young people's own leisure space was being entered, and access had been granted by adult gatekeepers, this period of 'hanging out' was critical to the formation of mutual respect and trust with young people and their youth workers. Time was taken to talk to all young people attending the club about the researcher's presence; everyday life in Robbiestoun; views on the research; and how (if at all) they would like to be involved. At the same time, research tools were incorporated into youth club sessions. Posters and leaflets were placed in visible spaces, serving as physical reminders about the research. A large map of the local area was also hung in the centre of the building. This was used as an initial prompt for conversations about the area, with young people being encouraged to add their views about the neighbourhood using coloured stickers and comments. Over the course of the fieldwork, the map served as a research 'hub', with emerging findings, photos, and anonymised quotes from participants being continuously displayed. A 'post box' (with blank postcards) was also placed in the youth club, with an invitation to write messages to adult decision makers in the neighbourhood.

The youth club was their space, their territory and, importantly, sessions represented their leisure time away from adults. Moreover, it was a busy location, with young people moving in and out of the research setting. Many young people attended sessions intermittently, and new faces would appear and disappear every week. Rather than imposing a structured approach to participation, the research was designed to fit into young peo-

\footnotetext{
${ }^{1}$ Several young people who attended the youth club expressed a preference for the term 'disadvantage' (over alternatives such as 'excluded', 'deprived' or 'poverty'). They felt that 'disadvantage' was associated to the area, not the individual deficits of residents. This rationale, with its recognition of the social and economic barriers facing young people, was in keeping with the emerging findings, and used by the researcher during the course of the study (Davidson, 2013a, p. 15).
} 
ple's patterns of socialisation. A range of activities were incorporated into the weekly sessions, and young people could choose whether, and how much, they wished to participate. The main activities included place mapping (using maps of the neighbourhood to discuss their views); walkabouts led by young people; individual photo diaries in which young people recorded a typical day or night out; as well as group discussions or informal conversations over coffee.

Sampling was opportunistic, and sought to talk to, and observe, young people who could illuminate understandings of young people's everyday interactions with antisocial behaviour. As the study progressed, project activities were extended to other spaces, including the local library and a detached youth work project. Efforts were made to ensure an equal split by age and gender, however, the population of Robbiestoun was predominantly White-Scottish and this was reflected in the ethnicity of the initial sample. In response to this, a youth club working specifically with black and minority ethic young people was included in the project. Overall, the approach allowed the research to engage with large numbers of young people over an extended period of time, with more than 70 young people participating in one or more task-based activity, and 38 individuals taking part in an interview. The majority of those interviewed were already well known to the researcher and had previously been involved in some element of the project.

The fieldwork concluded with 'Say It Like It Is', an art project aimed at enabling a small group of young people to collaborate in the analysis of the data. A general invitation to young people attending Robbiestoun Youth Centre was circulated, which resulted in a core group of five young people meeting weekly over nine sessions. Using a selection of materials produced during the research (anonymised text from interviews and group discussions, photos, maps and postcards) the group were asked to reflect on the broad research themes: young people's social relations; spaces and places for young people in Robbiestoun; feelings about growing up in the neighbourhood; and feelings about antisocial behaviour in their everyday lives. Working with a local artist, participants designed posters to respond to the findings, and express their views on these topics. Some young people collected their own materials to produce their posters, either by collecting objects or by taking their own photos. The research concluded with a public event at Robbiestoun Youth Centre which displayed the posters alongside the initial research findings. Key decision makers, including local councillors and police officers, attended the event, as did young people from the local area. Art activities were led by youth workers which allowed participants to comment on the various displays, and provide their own interpretation of the emerging findings. The young people's posters were subsequently exhibited for an extended period at the local community centre.

Reflecting the Economic and Social Research Council's Framework for Research Ethics (2015), consent to participate was seen as an ongoing and open-ended process, and not something resolved through the formal signing of a consent document at the start of research. The research regarded all young people as having the capacity to give consent to participate independently of their parents or guardians, although this was underpinned by clear written protocols on disclosures relating to harm and child protection. Special care was taken to develop an ongoing process of consent sensitive to the needs and capacities of different participants. This included ensuring my research posters were visible, handing out leaflets, and most importantly talking to young people about the research and how they could participate. Extended time undertaking fieldwork meant that most young people were exposed to the research over a long period of time and were provided with multiple opportunities to negotiate when they wished to participate and when they wished to 'opt out'.

This section has described in some detail the different elements of the research. In doing so, it highlights the complexities of defining participatory research in practice. Several typologies or models of participation (see Tisdall et al., 2014, for an overview) have sought to articulate different degrees of participation. These have largely been criticised for their linearity, and their tendency to classify research as becoming more participatory as power is relinquished by adults and passed to children and young people. The research discussed here is not unusual in that it encompassed several different elements, with varying degrees of participation and levels of engagement (collective and individual). In some cases, the degree of participation was constrained by funding, pragmatism and timescales. The research topic had, for example, been specified by the funders, while the Art Project which arguably involved young people in decision making in the most explicit way was funded separately, and had a small budget and limited timescales. The more realistic intention of the research was that less weight should be placed on efforts to equalise power between the researcher and participants, and more given to ensuring that there was a genuine and continued commitment to providing participants a choice in what they want to share, how they share it and then actively listening to what they say. The toolkit enabled this possibility, treating individual participants as actors and giving them ownership of those elements of the research they were involved in (see Aldridge, 2016, p. 156). The research was also explicit about the limits of its participatory possibilities. Rather than aiming to be as participatory as possible, it emphasised honesty in its intentions, in how participants' data would be used and the extent to which it could realistically effect change.

\section{Entering an Existing Landscape of Power}

Beyond a catchy headline, the research was presented as an opportunity to 'be heard', conceptualising young people as subject to control, and deprived of influence. 
While the methodology and epistemology had been researched, discussed and planned, initial experiences in the field felt far removed from these theoretical deliberations. The existence of power differentials was inevitable, yet the realities of navigating power within new research relationships was immediately challenging, as shown in fieldnotes taken during the first few weeks on-site:

None of them seemed that bothered about who I was or what I was doing. Attempts to talk about it were met with either silence or ambivalence. Issues of power need to be explored further. (Fieldnotes, week 1)

There are a few girls at the session today. It is difficult to talk to them. I try to introduce myself [to the group of girls] but they turn away and ignore me. I am left feeling stupid and totally powerless. It makes me think about the debates on participatory research ... that the researcher is powerful and subjects powerless. This is not straightforward-ideas of power are far more complex.' (Fieldnotes, week 2)

This unmistakably shows the balance of power in the researcher-participant relationship. In the first extract, I am an 'outsider': a middle class adult from 'the university', entering a young person's space on the basis of permissions granted by adult gatekeepers. In the second extract, the girls are swift to exercise their power using exclusionary social practices. Power, here, can be seen as a way of demonstrating a claim to the youth club (their space), their identities and their privacy.

In these early interactions and observations, it also became apparent that power dynamics were not only a feature of my relationships, but that they permeated young people's peer relations. They influenced when they visited the club, who they came with, and what they choose (or felt able) to do when they were there. June, for example, was very willing to participate in an interview, but felt unable to engage in group activities due abuse and bullying she had experienced at the hands of her peers:

I think, because they come here and they give me a black eye, they battered my pal and recently threatened to stab me, it's just like, why would I come down here, if they're using it to get rewarded for something'. (June, 16)

In another example, the balance of power operated in a different direction. When recruiting participants for the art project, a question young people often asked was, 'who else is taking part?'. One of the volunteers was identified as a 'geek' and a 'swot', the result being that several young people opted out as they did not wish to be seen 'hanging out' with this person (see also Davidson, $2013 b$ ). The outcome is that even those not participating in the project successfully exerted control over how the project was perceived, and the knowledge ultimately produced. The power dynamics fused within these examples reminds us that "research is a practice that is part of social life rather than an external contemplation of it" (Christensen, 2004, p. 166), with the observed interactions speaking more widely to the inequitable power differentials within young people's social relations and identities. Navigating these ethical dilemmas are not easily resolved, since attempting to create an inclusive, supportive environment may be empowering for some, yet result in greater control and influence over others.

\section{Refusals, Subversion and the Re-Appropriation of Power}

As the research progressed, young people continued to exercise power in multiple ways. Robert, for example, was keenly involved in my research, participating in group activities and an interview. However, towards the end of the fieldwork he announced 'I have helped you enough', at which point he had no further involvement in the research. On discussing this, he stated that the research had encouraged him to do things he had not done before, and share views on issues he had not considered. However, he felt he had 'said what he needed to say'. In another example, I spent the evening baking with Steph and a group of her friends. This was not a formal research activity, but we were discussing issues pertinent to the research. Whilst washing the dishes Steph told me:

I don't want you using the conversation we had tonight for your research, I haven't agreed to it being used, ok? (Steph, 14)

In both these cases, decisions to opt out provided positive indications that the participants understood they had agency in the research process, and that they could say 'no' without fear of it being viewed as an act of dissidence. Others took delight from resisting, rebelling and subverting the research process. During one mapping activity, two boys - Tommy and Bobby-sneaked off with my pens. Disappearing upstairs, they spent the time scribbling offensive comments on the youth club walls, an act especially telling given our activity that evening focused on 'graffiti as a form of antisocial behaviour'. A further example of rebellion took place during a detached session in a local park, where I was working alongside two youth workers. We provided a group of young people with chalk, and instructions for drawing an 'evolving image' over the paths. The group rejected our directions, and instead (with much hilarity) proceeded to spend the next hour drawing dozens of enormous 'cocks and tits' all over the park. Yet, on the same evening, the same group of young people sat down for a chat, and shared their resentment about being accused by the police of setting fire to a local football pitch:

Warren tells me that they were moved on by the police: 'They took our names; then moved us on. This 
happens all the time, and it know it is because of where I am from'. He is angry-he believes that he and his friends are unfairly targeted by the Police and by local residents. (Fieldnotes, week 18)

In these cases, the young people were not rejecting the research-but rather making it clear that the activity suggested was not how they wished to participate at that moment in time. Tommy and Bobby, for example, were frequently 'in trouble' with the police. They found participating in groups challenging, and were frequently excluded from youth services. The toolbox methods allowed different forms of participation, and it was during 'walking tours' where Tommy and Bobby exhibited confidence leading the group, expressing their views and their ideas. Warren and his friends, meanwhile, saw the youth workers and myself as entering their territory. They had had a recent altercation with the police, and combined with the wider context of surveillance and control in public spaces, they were initially hostile to participation. In this instance, understanding the context and respecting the group's desire to relax and have a laugh was central to engagement.

Other similar events took place during the fieldwork. One of the activities young people were invited to participate in was 'mapping' their local area. In groups, we looked at a large map of their community, marking places and spaces young people spent time in, those they liked and disliked, and those they felt were safe or unsafe. This was followed by walkabouts directed by the young people. For some, the exercise did not engage them. Maps were difficult to navigate in certain cases, and others were concerned that they would have to write to take part. A more pressing issue was that group discussions were easily dominated by the most powerful, often male, voices. On examining the maps after the sessions, I would find marginalia in the form of doodles around the edges of the maps and on post-it notes. Despite their relative silence in the session, these scribbles provided quieter young people a means through which to express their voice. Figure 1 shows examples of this marginalia: the first is a drawing is of a police officer with the accompa- nied text, 'I smell bacon', and the second depicts a local 'junky' (a negative colloquialism for a heroin user) carrying a bottle of vodka.

Opting into the research for diverse reasons was also encountered. While all regarded the topic as important to some extent, other reasons often had greater significance. Jules and Amy, for example, participated in the research because they thought it was fun. Robert was motivated by his 'crush' on Amy. Others, however, were driven by the offer of food provided as a 'thank you' for participating. In one activity, the group were determined in their efforts to provide only yes / no answers to get it 'over with as quickly as possible', asking repeatedly 'can I get my cake yet?'.

As in the work of Fine, Weis, Weseen and Wong (2000) subjects frequently exploited the knowledge that the research was recording their stories and their concerns. This impacted on power inequalities in different ways. In some instances, participants would be keen to tell tales from the weekend, to share examples of their interactions with the police, or adult members of the community. There were also several occasions when the young people would prey on my gullibility, for example, on one occasion Jack told an elaborate story about one of the group being imprisoned for murdering someone with a spoon. Afterwards, the group fell about the floor laughing, with Jack shouting 'why not put that in your book!'.

Key to managing such responses to the research was having an approach which was inherently flexible, and sensitive to the fact it was being conducted within young people's own territories, in spaces they had chosen to be. Thus, individuals like Robert could opt in (and out) depending on how they felt. By combining the toolkit of methods with participant observation, it became possible to adapt my approach according to the social and spatial context and young people's individual preferences.

\section{Negotiating My Role in the Field}

With such flexibility, of course, came ethical dilemmas in relation to my own identity and position in the research. Jack's comment-'why not put that it your book!'-
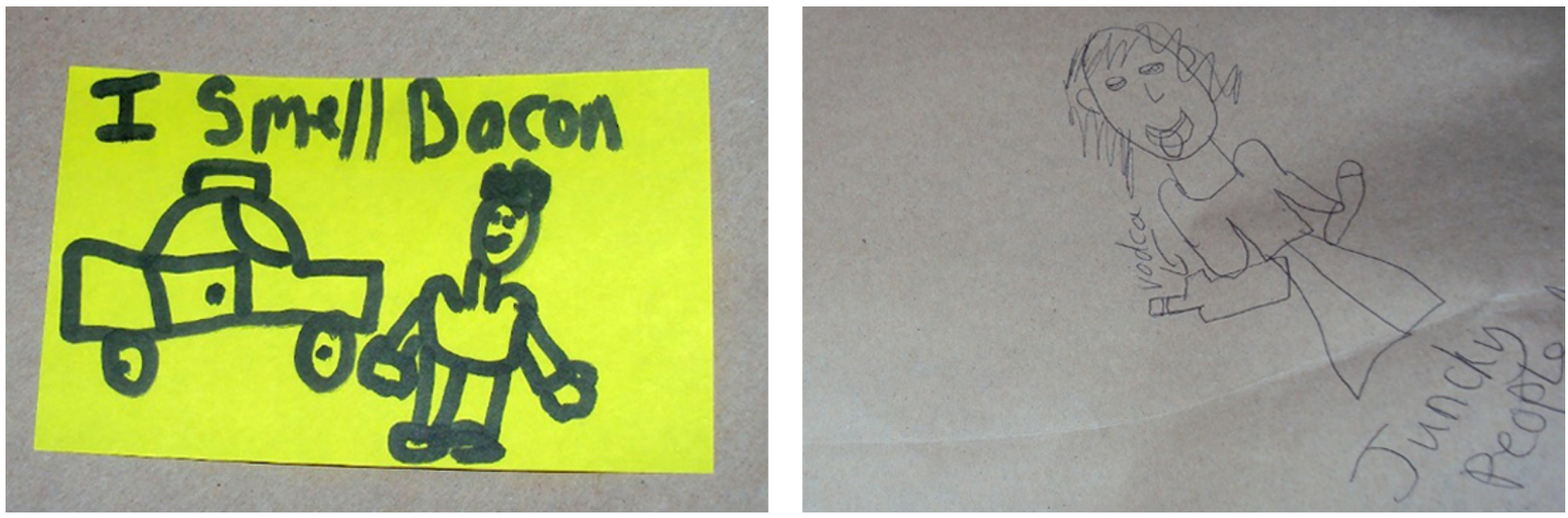

Figure 1. Marginalia produced during group mapping exercise. 
brought my reason for being in their space sharply into focus. While efforts were made to be honest about my presence, my identity was often ambiguous and required constant negotiation. This complexity was partly the result of my presence in multiple locations (fieldwork was conducted in youth clubs, the local library and on the street), and the use of diverse methods in these settings. 'Conventional' techniques used, such as interviews, were easily recognisable as 'research'. However, task-based activities were similar to the approaches used by youth workers, making my identity unclear and perhaps better aligned to the category of 'volunteer'. In one discussion with the youth workers we talked about how much young people understood who I was. One of the workers, Alex, turned to me and said 'stop worrying about it', adding 'let's face it you are a youth worker now, that's how they see you'.

While my attendance might have become normalised, there was nonetheless evidence that young people understood I was not a regular volunteer. For most I occupied a position of 'betweenness' (Barker \& Smith, 2001), falling somewhere between youth worker, friend and researcher. The following extract from a walkabout with Bobby demonstrates one such example of this:

We are taking a photo of a smashed window. Bobby says 'Do you want to go and smash a window now?'. Surprised (and laughing), I turn and ask him, 'who do you think I am?'. 'Dunno' he replies 'but we can take a photograph of it!' (Fieldnotes, week 15)

This desire to test the balance of power frequently surfaced. Young people recognised that, unlike a volunteer, I was less likely to reprimand or challenge their behaviour. Tests of my identity (and my patience) included stealing all the biscuits / pens / post-it notes for planned sessions; using a photo diary to take multiple photos of a cannabis joint; and 'stealing' my bike. I accepted these as part of my work in the field, and actively participated in the humour and laughter most of these acts provoked. However, on occasion they had wider, and less comedic, intentions, as the example below shows:

Abs was throwing pieces of a game at Henry. He is thought [by youth workers and other young people] to have been targeting his house and Henry told me he smashed the window of his house. From where I was sitting I could see him throwing the pieces hidden up his sleeve. Just before throwing each piece he would smile wryly at me-I was his accomplice. The youth worker came over and asked me to confirm that he was the culprit. I said I hadn't seen anything. (Fieldnotes, week 11)

This incident was significant. The request from the youth worker to provide information placed me in the position of spy. Yet it was equally problematic to align myself with Abs. By colluding with him I may win his trust, but at the same time would be seen to condone his behaviour and further marginalise Henry. As Abs's sly glances showed, he was attributing me a role in his actions. This interaction was later discussed with the youth worker, and provided a point through which to reflect on my identity and responsibilities within the field (both from my own, and the worker's perspective). In her research Mandell (1988) adopted what she calls 'the least adult role' in an attempt to distance herself from the authoritative, adult world. However, as Mayall (2000) points out there are inevitable differences between adults and children, a distinction that becomes particularly apparent when working with teenagers. The research was facilitated by youth work organisations and in this setting I was quite clearly an adult. I had no intention of befriending the young people I met; nor did I wish to 'hang out' with them as an equal. As a female academic in her 30 s, from 'the university' (as it was referred to by young people), my age, status and social position made this impossible. Rather, I wanted to develop a relationship that was based on honesty, openness and trust. Crucially, the youth work setting is characterised by interactions taking place between adults and young people. Sitting out, or attempting to be one of the kids, had even greater potential to impact on 'normal business'.

As my time in the field developed, I became more comfortable challenging young people's behaviour. I am not suggesting that I adopted the disciplinary responsibilities of a youth worker, but more readily drew an ethical or moral 'line' over certain behaviours I witnessed. Hobbs (1989, p. 12) notes that "racism marked the parameters of [his] involvement in the cultural milieu" and his protests, he felt, did result in the loss of trust and data. Part of the cultural milieu of a youth centre is that of young people debating ideas, views and opinions. The young men who attended the employability group would, in particular, recount tales of violence against women, racist attacks and homophobic remarks. While I had no text book response about how to deal with these issues, I would normally use them to generate a discussion or debate. One recurring example was the well held view amongst males attending the club that 'Polish people have stolen all our jobs'. Like youth workers, such comments were used to explore how young people had come to hold such opinions, the reasons for singling out the Polish community and their own personal experiences of seeking work.

In line with Fine and Sandstrom (1988, p. 17), methodological value was gained from maintaining the difference between myself and the young people, since it gave me permission to operate with an inquiring mind, to ask questions, engage with young people's points of view and, importantly, make mistakes. These interactions, for some young people, may have cemented my identity as an adult, however, I was rarely seen as an 'adult-incharge' (Johansson, 2012). To use Johansson's (2012) terminology, most often my role and positioning within the research was as 'adult-included-in-commonality', with 
games, jokes and playful exchanges being the mainstay of my relationship with participants.

\section{Saying It Like It Is?}

This paper began by discussing the place that power has in research with children and young people, and the ways, conceptually, it has contributed to understandings of participation. Researchers working within the 'new social studies of childhood' have largely embraced participatory research as a means through which to challenge the power imbalance between adult (researchers) and child (participants), and promote equality and empowerment. Particular weight has been given to 'creative' methods as a means through which to make children and young people's voices more authentic.

Critics have suggested that it is possible for research designed as participatory to create a generational divide based on a hierarchical notion of power. Not only does this assume that the movement of power is age related, but also that 'children and young people' are treated as a homogenous group. Skelton (2007), in her analysis of UNICEF's participatory discourses and practices, notes that participation too often becomes removed from its social, political and cultural context, and that it can, in different circumstances, mean different things to different young people. She also notes that with its concern about levelling power, participation can give more attention to positioning the adult correctly, than the experience of the young person (Skelton, 2007, p. 174).

There is also a view of participation, especially in the context of the $\mathrm{CRC}$, as being linked to the individual democratic rights of children (Cairns, 2006). With respect to Article 12, focus has been given to giving children and young people a 'voice' and children's 'right to participate' (Lundy, 2007, p. 942). Skelton (2007, pp. 176-78) suggests that this 'ideal' model of participation confirms established patterns and reduces the possibilities for creativity, resistance and rebellion. Similarities can be drawn to the connected concept of 'agency' which, like voice, is too frequently held out to be an "unquestionable good" endorsed by a rights discourse (Lundy, 2007, p. 931). This view of agency not only fails to recognise young people's right not to participate, but also potentially neglects those who are vulnerable or whose agency is bounded by structural constraints (Tisdall \& Punch, 2012). Bordonaro and Payne (2012, p. 386) have also argued that there is too often a presumption that children should show agency, but only when it is expressed in the expected or normatively 'correct' form. 'Ambiguous' or challenging forms of agency, meanwhile, are judged 'out of place' and inappropriate to decision makers and policy makers.

This study was adult-initiated, and did not involve young people in its planning or implementation. It is in this respect that it may be criticised for not being a 'pure' form of participatory research (Gallacher \& Gallagher, 2008). While the toolkit approach sought to re- spect participant's "time, capacity, resources and inclination to join in" (Alderson, 2012, p. 237), it was also constrained by the requirements of the funder, and associated timescales. While the fieldwork, overall, was flexible and iterative, for pragmatic reasons some elements were regulated-even controlled-by adults. Young people involved in the art project, for example, had only a short period of time to engage in the data, produce their posters and plan the exhibition, and as a consequence adults tightly structured sessions. Activities, such as mapping, were therefore restricted to the length of a session at the youth club. As such, research activities were often spent 'rounding up participants', keeping an eye on the clock, re-directing groups when they went 'off topic' and challenging acts of bullying and exclusion.

In the context of this work (a relatively short, time limited, exploratory study) it was accepted that the process was never going to be an equal one. However, the strength of the research came from its use of a toolkit approach which allowed diverse groups of young people to participate (or not) in ways appropriate to their needs, in spaces and places of their choosing. The creative methods gave access to aspects of young people's lives that otherwise may have been inaccessible through a 'conventional' qualitative study. Photo diaries, mapping and walking tours allowed for collective and individual insight into everyday life within Robbiestoun, narrated or visualised in ways meaningful to participants. Group activities, meanwhile, provided opportunities to engage in dynamic conversations and "collective knowledge production" (Horgan, 2017, p. 252). 'Deep participation' (Horgan, 2017), in this context, would have required more intensive work, with a smaller number of young people. Given the lack of research on young people's everyday experiences of antisocial behaviour, it was felt that such an approach would have narrowed the field and, in so doing, marginalised and excluded other voices, particularly those who had been victims of antisocial behaviour. Moreover, combining participatory methods with participant observation and interviews afforded the researcher a rich insight into everyday and informal forms of participation (Horgan et al., 2017; Tisdall et al., 2014).

This leads us to the question of how, and to what extent, method can impact on participation and power. Using examples of participatory research in practice, this article has argued that methods alone do not provide an easy resolution to inequality, nor do they necessarily empower. Young people-as can adults-participate, subvert, dominate and ignore research for different, and valid, reasons. Individual preferences and capacities can, for instance, impact on engagement. In this study many young people opted out of group activities, preferring instead to chat, informally, over coffee. Perhaps more critically, individual acts of resistance were not a straightforward reaction to how participatory the project was, or claimed to be, but rather were etched with intersecting lines of power associated to age, class, gender, race, place, and a host of other identities. 
While it is not correct to suggest that resistance is peculiar to disadvantaged areas, in the context of this research the young people who frequently resisted and subverted the process also tended to be those who were most vulnerable and marginalised. Notably, their resistance was not unique to the research: youth workers with whom they enjoyed supportive relationships faced similar challenges engaging them in projects or organised activities. Tommy, Bobby, and others like them, were not resisting methods per se. Rather, their acts were an expression of their power(lessness), both within the group and wider society. Thus, while rebellion and ambiguous agency was frustrating from the perspective of the research, on reflection, these responses provided insight into young people's social worlds, their claims for status, identity and belonging in the context of a disadvantaged place.

Participatory research cannot straightforwardly seek to ameliorate these intersecting power differentials: rather its importance lies in its ability to expose inequalities, prompt reflexivity and begin the journey towards emancipation, social change and critical consciousness (Gaventa \& Cornwall, 2008, p. 72). The aim, then, is not only to recognise that participatory research can assume different forms and use a multiplicity of methods (both individual and collective), but that good quality participation is heavily dependent on the ethos of those conceptualising and designing it (Cornwall \& Jewkes, 1995, p. 1667), be it a community group, youth club or academic researcher. Most importantly is that participation should be approached in a way that opens up possibilities for creativity, resistance, rebellion-with space for fun and humour along the way. Such flexibility and responsivity demands both ethical rigour and consideration of exclusionary practices between participants, since rather than reducing or minimising power, it embraces it as a fundamental aspect of research, and of wider society.

\section{Acknowledgments}

This research was supported by an Economic Social Research Council grant (ES/F032013/1). The author would like to thank the reviewers for their insightful comments on an earlier version of this manuscript, and for the ongoing support of Professor Lynn Jamieson and Professor Kay Tisdall, both University of Edinburgh. Finally, and most importantly, thanks are given to the young people who participated in this research with enthusiasm, fun and laughter.

\section{Conflict of Interests}

The author declares no conflict of interests.

\section{References}

Alanen, L. (2014). Theorizing childhood. Childhood, 21(1), 3-6.
Alderson, P. (2012). Rights-respecting research: a commentary on 'the right to be properly researched: research with children in a messy, real world', Children's Geographies, 2009, 7, 4. Children's Geographies, 10(2), 233-239.

Aldridge, J. (2012). The participation of vulnerable children in photographic research. Visual Studies, 27, 48-58.

Aldridge, J. (2016). Participatory research: Working with vulnerable vroups in research and practice. Bristol: Policy Press.

Askins, K., \& Pain, R. (2011). Contact zones: Participation, materiality and the messiness of interaction. Environment and Planning D: Society and Space, 25(5), 803-821.

Barker, J., \& Smith, F. (2001). Power, positionality and practicality: Carrying out fieldwork with children. Ethics, Place \& Environment, 4(2), 142-147.

Barker, J., \& Weller, S. (2003). "Is it fun?" Developing children centred research methods. International Journal of Sociology and Social Policy, 23(1), 33-58.

Bordonaro, L. I., \& Payne, R. (2012). Ambiguous agency: Critical perspectives on social interventions with children and youth in Africa. Children's Geographies, 10(4), 365-372.

Cairns, L. (2006). Participation with purpose. In J. Davis, M. Hill, K. Tisdall, \& A. Prout (Eds.), Children, young people and social inclusion: Participation for what? (pp. 217-234). Bristol: Policy Press.

Cameron, C. A., Theron, L., Tapanya, S., Li, C., Lau, C., Liebenberg, L., \& Ungar, M. (2013). Visual perspectives on Majority-World adolescent thriving. Journal of Research on Adolescence, 23(1), 149-161.

Cashmore, J. (2002). Promoting the participation of children and young people in care. Child Abuse \& Neglect, 26(8), 837-847.

Christensen, P. H. (2004). Children's participation in ethnographic research: Issues of power and representation. Children \& Society, 18(2), 165-176.

Christensen, P. H., \& James, A. (Eds.). (2008). Research with children: Perspectives and practices. London: Falmer Press.

Coad, J. (2007). Using art-based techniques in engaging children and young people in health care consultations and/or research. Journal of Research in Nursing, 12(5), 487-497.

Cooke, B., \& Kothari, U. (2001). The case for participation as tyranny. In B. Cooke \& U. Kothari (Eds.), Participation: The new tyranny? (pp. 1-13). London: Zed Books.

Cornwall, A., \& Jewkes, R. (1995). What is participatory research?. Social Science \& Medicine, 41(12), 667-676.

Damer, S. (1989). From Moorepark to "Wine Alley". Edinburgh University Press: Edinburgh.

Davidson, E. (2013a). Young people and the everyday antisocial (Unpublished Thesis). Edinburgh University, Edinburgh, UK. 
Davidson, E. (2013b). Between edges and margins: Exploring 'ordinary' young people's experiences of the everyday antisocial. Sociological Research Online, 18(1).

Economic and Social Research Council. (2015). Economic and Social Research Framework for Research Ethics. London: ESRC.

Fine, G. A., \& Sandstrom, K. L. (1988). Knowing children: Participant observation with minors. London: Sage.

Fine, M., Weis, L., Weseen, S., \& Wong, L. (2000). Qualitative research, representations and social responsiblities. In N. K. Denzin \& Y. S. Lincoln (Eds.), Handbook of qualitative research. London: Sage.

Flint, J., \& Nixon, J. (2006). Governing neighbours: Antisocial behaviour orders and new forms of regulating conduct in the UK. Urban Studies, 43(5/6), 939-955.

Freeman, C., Nairn, K., \& Sligo, J. (2003). 'Professionalising' participation: From rhetoric to practice. Children's Geographies, 1(1), 53-70.

Gallagher, M. (2008). Power is not an evil: Rethinking power in participatory methods. Children's Geographies, 6(2), 137-150.

Gallacher, L. A., \& Gallagher, M. (2008). Methodological immaturity in childhood research? Thinking through 'participatory methods'. Childhood, 15(4), 499-516.

Gaventa, J., \& Cornwall, A. (2008). Power and knowledge. In P. Reason \& H. Bradbury (Eds.), The SAGE handbook of action research: Participative inquiry and practice. London: Sage.

Grover, S. (2004). Why won't they listen to us? Childhood, 11(1), 81-93.

Guariento, G. F. (2010). Without a safety net: Participatory techniques in research with young migrants. $E N$ QUIRE, 5.

Hanson, K. (2016). Children's participation and agency when they don't 'do the right thing'. Childhood, 23(4), 471-475.

Harden, J., Scott, S., Backett-Milburn, K., \& Jackson, S. (2000). Can't talk, won't talk?: Methodological issues in researching children. Sociological Research Online, $5(2)$.

Hill, L. C. (2012). Revealing lives: A qualitative study with children and young people affected by parental alcohol problems (Unpublished Thesis). Edinburgh University, Edinburgh, UK.

Hill, M. (2006). Children's voices on ways of having a voice. Childhood, 13(1), 69-89.

Hobbs, D. (1989). Doing the business: Entrepreneurship, the working class, and detectives in the East End of London. Oxford and New York: Oxford University Press.

Holland, S., Renold, E., Ross, N. J., \& Hillman, A. (2010). Power, agency and participatory agendas: A critical exploration of young people's engagement in participative qualitative research. Childhood, 17(3), 360-375.

Horgan, D. (2017). Child participatory research methods: Attempts to go 'deeper'. Childhood, 24(2), 245-259.
Horgan, D., Forde, C., Martin, S., \& Parkes, A. (2017). Children's participation: Moving from the performative to the social. Children's Geographies, 15(3), 274-288.

James, A. (2007). Giving voice to children's voices: Practices and problems, pitfalls and potentials. American Anthropologist, 109(2), 261-272.

James, A., Jenks, C., \& Prout, A. (1998). Theorizing childhood. Cambridge: Polity Press.

Johansson, B. (2012). Doing adulthood in childhood research. Childhood, 19(1), 101-114.

Kellett, M. (2010). Rethinking children and research: Attitudes in contemporary society. London and New York: Continuum International Publishing Group.

Komulainen, S. (2007). The ambiguity of the child's 'voice' in social research. Childhood, 14(1), 11-28.

Lundy, L. (2007). 'Voice' is not enough: conceptualising Article 12 of the United Nations Convention on the Rights of the Child. British Educational Research Journal, 33(6), 927-942.

Maguire, G. (2008). Doing participatory research: A feminist approach. In A. M. Jaggar (Eds.), Just methods: An interdisciplinary feminist reader. Boulder, CO: Paradigm Publishers.

Mandell, N. (1988). The least-adult role in studying children. Journal of Contemporary Ethnography, 16(4), 433-467.

Matthews, H., Limb, M., \& Taylor, M. (1999). Young people's participation and representation in society. $\mathrm{Ge}$ oforum, 30(2), 135-144.

Mayall, B. (2000). Conversations with children: Working with generational issues. In P. M. Christensen \& A. James (Eds.), Research with children: Perspectives and practices. London: Falmer Press.

Morrow, V., \& Richards, M. (1996). The ethics of social research with children: An overview. Children and Society, 10(2), 28-40.

Nelson, N., \& Wright, S. (1995). Participation and power. In N. Nelson \& S. Wright (Eds.), Power and participatory development: Theory and practice (pp. 1-18). London: Intermediate Technology Publications.

Pain, R. (2004). Social geography: Participatory research. Progress in Human Geography, 28(5), 652-663.

Pain, R., \& Francis, P. (2003). Reflections on participatory research. Area, 35(1), 46-54.

Percy-Smith, B., \& Thomas, N. (Eds.). (2010). A handbook of children and young people's participation. London: Routledge.

Plows, V. (2012). Conflict and coexistence: Challenging interactions, expressions of agency and ways of relating in work with young people in the Minority World. Children's Geographies, 10(3), 279-291.

Punch, S. (2002). Research with children: The same or different from research with adults? Childhood, 9(3), 321-341.

Qvortrup, J. (2009). Are children human beings or human becomings? A critical assessment of outcome thinking. Rivista Internazionale di Scienze Sociali, 117(3/4), 631-653. 
Roberts, H. (2000). Listening to children: And hearing them. In P. Christensen \& A. James (Eds.), Research with children: Perspectives and practices. London: Falmer Press.

Ryan, P. J. (2008). How new is the "new" social study of childhood? The myth of a paradigm shift. The Journal of Interdisciplinary History, 38(4), 553-576.

Shier, H. (2001). Pathways to participation: Openings, opportunities and obligations. Children \& Society, 15(2), 107-117.

Sinclair, R. (2004). Participation in practice: Making it meaningful, effective and sustainable. Children \& Society, 18(2), 106-118.

Skelton, T. (2007). Children, young people, UNICEF and participation. Children's Geographies, 5(1/2), 165-181.

Soto, L. D., Swadener, B. B., Kincheloe, J. L., \& Jipson, J. A. (Eds.). (2005). Power and voice in research with children. New York: Peter Lang Publishing Inc.

Spyrou, S. (2011). The limits of children's voices: From authenticity to critical, reflexive representation. Childhood, 18(2), 151-165.

Squires, P. (Ed.). (2008). ASBO nation: The criminalisation of nuisance. Bristol: Policy Press.

Thomson, F. (2007). Are methodologies for children keeping them in their place? Children's Geographies, 5(3), 207-218.
Tisdall, E. K. M. (2008). Is the honeymoon over? Children and young people's participation in public decisionmaking. International Journal of Children's Rights, 16(3), 419-430.

Tisdall, E. K. M. (2015). Participation, rights and 'participatory' methods. In A. Farrell, S. L. Kagan, \& E. K. M. Tisdall (Eds.), The SAGE handbook of early childhood research. London: Sage.

Tisdall, E. K. M., Gadda, A. M., \& Butler, U. M. (Eds.). (2014). Children and young people's participation and its transformative potential: Learning from across countries. Basingstoke: Palgrave Macmillan.

Tisdall, E. K. M., \& Punch, S. (2012). Not so 'new'? Looking critically at childhood studies. Children's Geographies, 10(3), 249-264.

Uprichard, E. (2008). Children as 'being and becomings': Children, childhood and temporality. Children \& Society, 22(4), 303-313.

Van Blerk, L., \& Kesby, M. (2009). Doing children's geographies: Methodological issues in research with young people. London and New York: Routledge.

Wickenden, M., \& Kembhavi-Tam, G. (2014). Ask us too! Doing participatory research with disabled children in the global south. Childhood, 20(4), 400-417.

Wyness, M. (2013). Children's participation and intergenerational dialogue: Bringing adults back into the analysis. Childhood, 20(4), 429-442.

\section{About the Author}

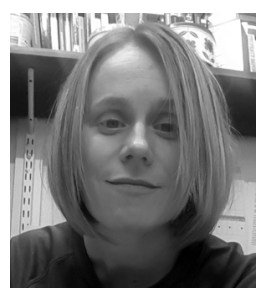

Emma Davidson (PhD) is a Leverhulme Early Career Research Fellow in Sociology, based at the Centre for Research on Families and Relationships at the University of Edinburgh. Her work straddles childhood, youth and community studies, and she has expertise in collaborative ethnography, participatory research methods, computer-assisted qualitative data analysis software, and secondary analytic practice. 